\title{
Chemotherapy of Locally Advanced or Metastatic Urothelial Cell Carcinoma: Monocentric Real-Life
} Data

\section{Christine Fischer \\ Rainer Hofmann \\ Axel Hegele}

Department of Urology and Pediatric Urology, University Medical Center, Marburg, Germany
Correspondence: Christine Fischer Department of Urology and Pediatric Urology, University Medical Center, Baldingerstraße, Marburg, Germany Email Christine.a.m.fischer@gmail.com
This article was published in the following Dove Press journal: Cancer Management and Research

Background/Aim: Up to $30 \%$ of all patients will present with an advanced or a metastatic stage (mUCC) at the moment of the initial diagnosis of urothelial cell carcinoma of the bladder (UCC). We investigated the numbers, the efficacy and toxicity of different chemotherapies for mUCC in daily practice and "real-life" conditions and evaluated them substance-specifically. Patients and Methods: All patients with a mUCC, who were treated between January 1, 2006 and October 31, 2016 at the Department of Urology and Pediatric Urology at University Hospital Marburg (Germany), were retrospectively analyzed. We set the focus on demographic and tumor-specific data as well as on effectiveness, therapy sequences, and drug tolerance.

Results: Forty-one patients were identified. Of the 41 patients, $85.4 \%$ of the patients in firstline therapy received gemcitabine/cisplatin. A large proportion of $85.4 \%$ received a secondline therapy and $40 \%$ a third-line therapy due to progress or relapse. Median overall survival (mOS) was 18 months including all patients and increased up to 29.5 months in the cases of three therapy lines.

Conclusion: Our data reveal that chemotherapy of mUCC is effective and side effects are manageable in daily clinical practice.

Keywords: urothelial carcinoma, metastatic urothelial carcinoma, bladder cancer

\section{Introduction}

Urothelial cell carcinoma of the bladder (UCC) is the second most common urological malignant tumor. In Germany, in 2014, invasive UCC had an incidence of 15,800 and a mortality rate of 5,692 patients. ${ }^{1}$ So UCC represents a highly aggressive malignancy and a medical challenge.

In cases of localized UCC, radical cystectomy offers the opportunity for cure. But 5 -year relapse-free survival following radical cystectomy is only between $60 \%$ and $70 \%$ and decreases to between $22 \%$ and $60 \%$ in cases of initial pT3b/pT4tumors or pelvic lymph node involvement. ${ }^{2-6}$ The prognosis of metastatic UCC (mUCC) is dismal, as median survival time of untreated mUCC rarely exceeds 3 months. Cisplatin-based polychemotherapy represents the standard in first line treatment of mUCC but median overall survival (mOS) was limited to about 15 months and longterm survival as well as progression-free survival (PFS) are low. ${ }^{7}$ In case of relapse or progression vinflunine (VFL), that was approved in 2009, or gemcitabine/paclitaxel $(\mathrm{G} / \mathrm{P})$ was recommended as well as immunotherapy agents more recently. ${ }^{8-10}$ Our retrospective analysis only includes data about chemotherapy as immunotherapy was not yet approved by the time of data collection. Data about number of reached therapy 
lines and association with overall survival (OS), response rates, survival data and side effects in daily clinical routine are rare. In the last few years "real life" data have become more interesting due to a lot of patients treated in daily practice who are not represented in Phase III studies because of age, comorbidities and other reasons. So currently "reallife" data, especially in the field of drug therapy in urooncology, have become more and more important in treating patients outside of clinical studies to get reliable data.

In this work, "real-life" data of mUCC treatment before approval of immunotherapy agents -was assessed and analyzed focusing on number of treatment lines, efficacy, and side effects.

\section{Patients and Methods}

In this retrospective analysis, we enrolled every patient with mUCC, who received treatment at the Department of Urology and Paediatric Urology, University Hospital Marburg (Germany) outside clinical studies between January 2006 and October 2016.

The data included demographic characteristics, kind of chemotherapy in first, second and third line, corresponding number of applied treatment cycles, response to therapy and therapy-associated side effects.

Data were gathered using the clinical data system ORBIS ${ }^{\circledR}$ (Agfa HealthCare $\mathrm{GmbH}$ ) and the patient paper files.

Treatment efficacy was based on objective response rate (ORR), disease control rate (DCR), OS and PFS. For patients who were still alive at the end of our analysis, OS was censored at this date. Treatment safety was examined by analyzing the prevalence of grade 3 or 4 toxicity. The severity of toxicity was defined by the physician in charge at every physician-patient consultation based on CTCAE (Version 4.03, June 2016).

Statistical analyses and survival functions (KaplanMeier method) were conducted using GraphPad Prism $6^{\circledR}$ (GraphPad Software, Inc.). Differences between more than two sample sizes were checked for significance by KruskalWallis-test. When the result was meaningful, an individual comparison was conducted using the Mann Whitney $U$-test. The significance level was determined as $p<0,05$.

\section{Results}

\section{Patient Data}

In the mentioned time period, 41 patients suffering mUCC received systemic medical therapy. The majority of the "real life" population were men $(80 \%, n=33)$ with a female to male ratio of $0.24: 1$. Median age was 66 years. In $66 \%$ of the patients $(n=27)$ the original tumor was localized in the lower urinary tract, in $22 \%(n=9)$ in the upper urinary tract and $12 \%(n=5)$ showed metachronous occurrence of upper and lower urinary tract UCC. At initial diagnosis of UCC $27 \%$ of the patients $(\mathrm{n}=11)$ already suffered from metastases. Patient data are summarized in Table 1.

\section{Number and Kind of Therapy Lines}

After first-line therapy, $84.5 \%(n=35)$ of the initial cohort reached second-line therapy and $40 \%(n=14)$ received a thirdline therapy in case of progression or relapse. Only two patients of these patients $(14.3 \%)$ reached fourth line treatment.

In first line $100 \%$ of the patients were treated with platinbased polychemotherapy: $85 \%(n=35)$ with a combination of gemcitabine/cisplatin $(\mathrm{G} / \mathrm{C})$ and $15 \% \quad(\mathrm{n}=6)$ with a combination of gemcitabine/carboplatin $(\mathrm{G} / \mathrm{Cp})$ due to reduced renal function.

Table I Baseline Characteristics of the Treated mUCC Patients

\begin{tabular}{|l|c|}
\hline Patient data & $\%(\mathbf{N})$ \\
\hline Gender & \\
\hline Female & $20(8)$ \\
\hline Male & $80(33)$ \\
\hline Median age & 66.0 \\
\hline Initial UCC location & \\
\hline Lower urinary tract & $66(27)$ \\
\hline Upper urinary tract & $22(9)$ \\
\hline Upper and lower urinary tract & $12(5)$ \\
\hline Metastatic disease at initial diagnosis & $27(11)$ \\
\hline Type of first line therapy & $85(35)$ \\
\hline G/C & $15(6)$ \\
\hline G/Cp & \\
\hline Type of second line therapy & $21(3)$ \\
\hline VFL & $54(19)$ \\
\hline G/P & $37(13)$ \\
\hline Other & $9(3)$ \\
\hline Type of third line therapy & \\
\hline VFL & \\
\hline G/P & \\
\hline Other & \\
\hline
\end{tabular}

Abbreviations: $G / C$, gemcitabine/cisplatin; G/Cp, gemcitabine/carboplatin; VFL, vinflunine; G/P, gemcitabine/paclitaxel. 
During the time period analyzed second-line therapy changed in favor of VFL after its approval in 2009: 54\% of the patients $(n=19)$ received VFL and $37 \%(n=13)$ received a combination of $\mathrm{G} / \mathrm{P}$ in the second-line setting. The remaining patients were treated with $\mathrm{G} / \mathrm{C}$-rechallenge $(3 \%, \mathrm{n}=1)$, paclitaxel $(3 \%, \mathrm{n}=1)$ or gemcitabine as a monotherapy $(3 \%, \mathrm{n}=1)$.

In third-line therapy, $43 \%(\mathrm{n}=6)$ received VFL, $36 \%(\mathrm{n}=5)$ $\mathrm{G} / \mathrm{P}$ and $21 \%(\mathrm{n}=3)$ another substance. In the fourth-line therapy, one patient received gemcitabine as a monotherapy and one patient was treated with MVAC (see Table 1).

\section{Overall Efficacy}

Median follow-up was 18 months (range 0.5-153). At the last follow up two patients $(4.8 \%)$ were still alive, and 39 patients $(95.2 \%)$ had died.

mOS was 18 months regarding all patients. The mOS were 10.8 months, 19 months and 29.5 months for patients receiving first-, second- and third-line therapy respectively. The mOS difference between one and three therapy lines was statistically significant $(p=0.041$, see Figure 1$)$.

\section{Therapy Line and Substance-Related Drug Efficacy and Toxicity}

First Line

Patients who were treated in first line showed a median PFS (mPFS) of 9.5 months (range $0.5-110$ ) and a mOS of 21.5 months $(0.5-145)$. ORR was $68.3 \%(\mathrm{n}=28)$ : complete response (CR) occurred in $22.0 \%$ of the patients $(n=9)$ and partial response (PR) in $46.3 \%$ of the patients $(\mathrm{n}=19)$. Stable disease (SD) was evident in $12.2 \%(n=5)$.

\section{$\mathrm{G} / \mathrm{C}$}

A total of 35 patients $(85.4 \%)$ were treated with $\mathrm{G} / \mathrm{C}$ in first line with a median of 4 cycles (range 1-8). mPFS was 8.5 months and mOS was 25 months. ORR was $68.6 \%$ $(\mathrm{n}=24): 22.9 \%(\mathrm{n}=8)$ had a $\mathrm{CR}$ and $45.7 \%(\mathrm{n}=16)$ a PR. DCR was $82.9 \%(\mathrm{n}=29)$.

Hematotoxicity was the most frequent therapyassociated side effect: patients in first line had an anaemia grade $\geq 3$ in $28.6 \%(\mathrm{n}=10)$ followed by thrombocytopenia $\geq 3$ in $20 \%(n=7)$. A leukopenia grade $\geq 3$ occurred in 31.5 of the patients $(\mathrm{n}=11)$ and a neutropenia $\geq 3$ in $36.1 \%$ $(\mathrm{n}=13)$. One patient sustained a febrile neutropenia. Overall, $91.4 \%$ of the patients $(\mathrm{n}=32)$ receiving $\mathrm{G} / \mathrm{C}$ as first-line therapy were treated with second line in case of progress or disease recurrence.
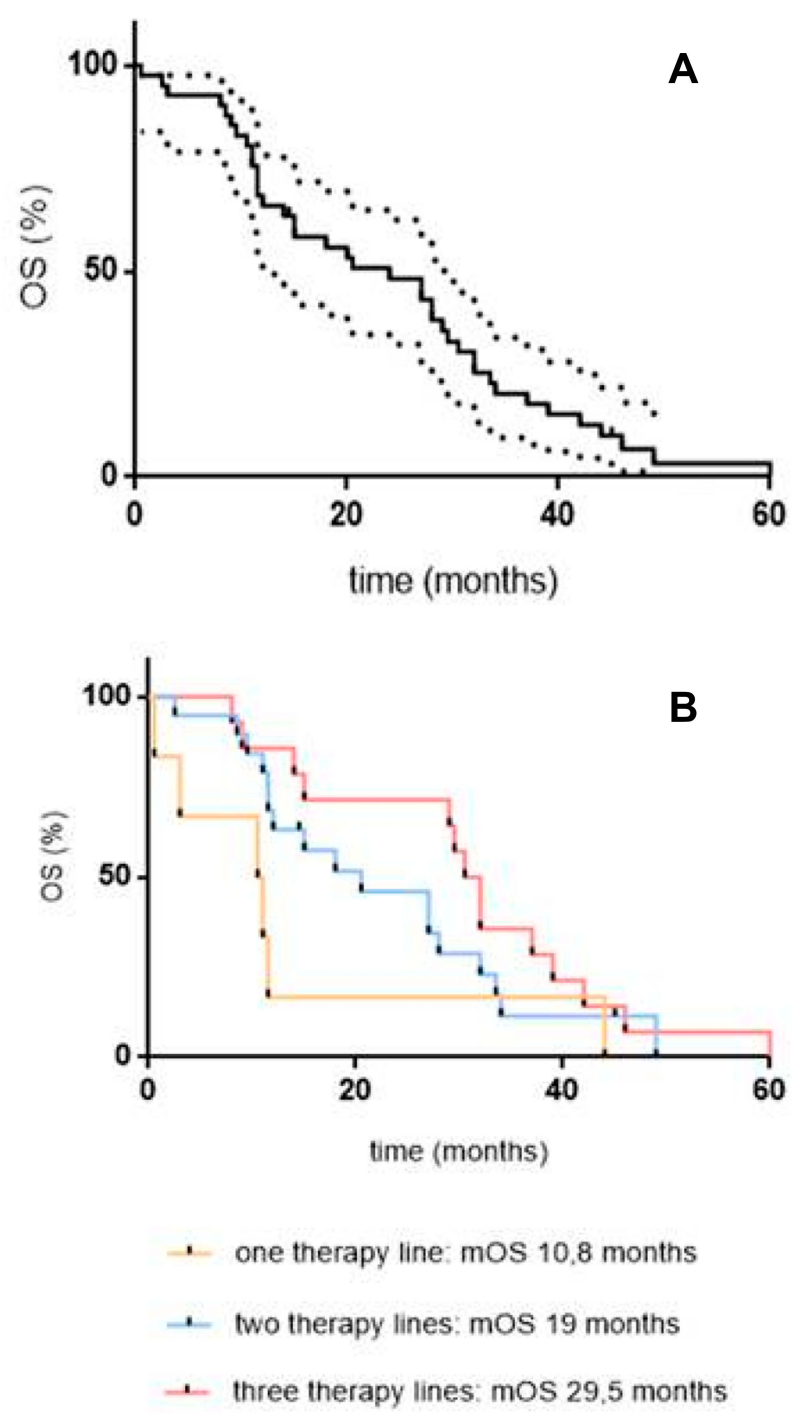

Figure I (A) OS of entire cohort, mOS 18 months and (B) mOS depending on therapy lines.

\section{$\mathrm{G} / \mathrm{Cp}_{\mathrm{p}}$}

Only six patients were treated with a median of 4 cycles (range 1-6) in first line. mOS and mPFS were 12 months each. ORR and DCR were $66.7 \%(\mathrm{n}=4)$ respectively: $16.7 \%(\mathrm{n}=1)$ showed a $\mathrm{CR}$ and $50 \% \quad(\mathrm{n}=3)$ a PR. Hematotoxicity was the most frequent side effect: patients had an anaemia grade $\geq 3$ in $50 \%(\mathrm{n}=3)$. A thrombocytopenia $\geq 3$ occurred in $66.7 \%$ of the patients $(n=4)$. Likewise, a leukopenia and neutropenia grade $\geq 3$ occurred in $66.7 \%$ of the patients $(n=4)$ respectively. One patient sustained a febrile neutropenia. Half $(50 \%)$ of the patients received second-line therapy after progress or disease recurrence.

Data of first-line therapy are summarized in Table 2. 
Table 2 Response Rate, Efficacy and Hematotoxicity in First, Second and Third Line

\begin{tabular}{|c|c|c|c|c|c|c|}
\hline & \multicolumn{2}{|l|}{ First Line } & \multicolumn{2}{|l|}{ Second Line } & \multicolumn{2}{|l|}{ Third Line } \\
\hline & $G / C(n=35)$ & $G / C_{p}(n=6)$ & $G / P(n=\mid 3)$ & VFL $(n=19)$ & $G / P(n=5)$ & VFL $(n=6)$ \\
\hline \multicolumn{7}{|l|}{ Response rate (\%) } \\
\hline$C R$ & $22.9(n=8)$ & $16.7(n=1)$ & $7.7(n=1)$ & $10.5(n=2)$ & $20(n=1)$ & - \\
\hline PR & $45.7(n=16)$ & $50(n=3)$ & $15.4(n=2)$ & $21.1(n=4)$ & $20(n=1)$ & $16.7(n=1)$ \\
\hline ORR & $68.6(n=24)$ & $66.7(n=4)$ & $23.1 \quad(n=3)$ & $31.6(n=6)$ & $40(n=2)$ & $16.7(n=I)$ \\
\hline SD & $14.3(n=5)$ & - & $30.8(n=4)$ & $26.3(n=5)$ & - & $33.3(n=2)$ \\
\hline DCR & $82.9(n=29)$ & $66.7(n=4)$ & $53.9(n=7)$ & $57.9(n=11)$ & $40(n=2)$ & $50(n=3)$ \\
\hline PD & $14.3(n=5)$ & $16.7(n=1)$ & $38.5(n=5)$ & $36.8(n=7)$ & $60(n=3)$ & $16.7(n=1)$ \\
\hline Discontinuation due to worsening of symptoms & $2.9(n=1)$ & $16.7(n=1)$ & $7.7(n=1)$ & $5.3(n=1)$ & - & $33.3(n=2)$ \\
\hline mOS (months) & 25 & 12 & 7.5 & 8 & 3 & 10 \\
\hline mPFS (months) & 8.5 & 12 & 7 & 5 & 3 & 3.3 \\
\hline \multicolumn{7}{|l|}{ Hematotoxicity } \\
\hline \multicolumn{7}{|l|}{ Anaemia } \\
\hline Grade 3 & $28.6(n=10)$ & $33.3(n=2)$ & $7.7(n=1)$ & $21.1(n=4)$ & - & $50(n=3)$ \\
\hline Grade 4 & - & $16.7(n=1)$ & - & - & - & - \\
\hline \multicolumn{7}{|l|}{ Thrombocytopenia } \\
\hline Grade 3 & II.4 (n=4) & $16.7(n=1)$ & $7.7(n=1)$ & - & - & - \\
\hline Grade 4 & $8.6(n=3)$ & $50(n=3)$ & $7.7(n=1)$ & $5.3(n=1)$ & - & - \\
\hline \multicolumn{7}{|l|}{ Leucopenia } \\
\hline Grade 3 & $28.6(n=10)$ & $33.3(n=2)$ & $30.8(n=4)$ & $21.1 \quad(n=4)$ & $40(n=2)$ & $33.3(n=2)$ \\
\hline Grade 4 & $2.9(n=1)$ & $33.3(n=2)$ & - & $10.5 \quad(n=2)$ & - & $16.7(n=1)$ \\
\hline \multicolumn{7}{|l|}{ Neutropenia } \\
\hline Grade 3 & $25.7(n=9)$ & $16.7(n=1)$ & $38.5(n=5)$ & $15.8(n=3)$ & - & $50(n=3)$ \\
\hline Grade 4 & II.4 (n=4) & $50(n=3)$ & - & $15.8(n=3)$ & $40(n=2)$ & - \\
\hline Febrile & $2.9(n=1)$ & $16.7(n=1)$ & $7.7(n=1)$ & - & - & - \\
\hline
\end{tabular}

Abbreviation: PD, progressive disease.

\section{Second Line}

Patients who were treated in second line $(84.5 \%)$ showed a mPFS of 5 months (range 1-50) and a mOS of 7 months (1-52). ORR was $31.4 \%(n=11)$ and $31.4 \%(n=11)$ had a SD.

\section{G/P}

Thirteen patients (37.1\%) were treated with a median of 4 cycles (range 1-13). mPFS was 7 months and mOS was 7.5 months. ORR was $23.1 \%(\mathrm{n}=3): 7.7 \%(\mathrm{n}=1)$ had a $\mathrm{CR}$, $15.4 \%(n=2)$ had a PR. DCR was $53.9 \%(n=7)$.

Hematotoxicity was the most common side effect under G/P: $7.7 \%(\mathrm{n}=1)$ had an anaemia grade 3. Likewise, $7.7 \%$ $(n=1)$ sustained a thrombocytopenia grade 3 and 4 in each case, while $30.8 \%(\mathrm{n}=4)$ of the patients suffered from a leukopenia grade 3 and $38.5 \%(n=5)$ had a grade 3 neutropenia. One patient experienced a febrile neutropenia.

\section{VFL}

A median of 7 cycles (range 1-27) were applied in second line to 19 patients $(54.3 \%)$. mOS was 8 months, mPFS was 5 months. ORR was $31.6 \%(\mathrm{n}=6): 10.5 \%(\mathrm{n}=2)$ had a $\mathrm{CR}$, $21.1 \%(\mathrm{n}=4)$ had a PR. DCR was $57.9 \%(\mathrm{n}=11)$. The following side effects occurred: $21.1 \%(n=4)$ had an episode of constipation grade 3 . All patients were treated with a laxative during chemotherapy. Hematotoxicity occurred most frequently: one patient had a thrombocytopenia, $21.1 \%(\mathrm{n}=4)$ had an anaemia and $31.6 \%(n=6)$ experienced a neutropenia.

Data of second-line therapy are summarized in Table 2.

\section{Third Line}

mPFS in third line was 3 months (range 0.5-16.5) and mOS was 8.5 months (range 0.5-28.5). ORR was $27.3 \%$ $(n=3)$ and DCR was $45.5 \%(n=5)$. 


\section{$\mathrm{G} / \mathrm{P}$}

A total of five patients $(35.7 \%)$ were treated with a median of 4 cycles (range 1-10). mPFS and mOS in third line amounted to 3 months. ORR and DCR was $40 \%(n=2)$ : $20 \%(n=1)$ had a CR, $20 \%(n=1)$ had a PR. For rates of hematotoxicity see Table 2 .

\section{VFL}

Six patients $(42.9 \%)$ received 5 cycles in median (range 1-22). mOS was 10 months and mPFS was 3.3 months. ORR and DCR were $16.7 \%(\mathrm{n}=1)$ and $50 \%(\mathrm{n}=3)$ respectively. Overall, $16.7 \%$ of the patients $(\mathrm{n}=1)$ had a PR while $16.7 \%$ of the patients $(n=1)$ experienced a progressive disease. For rates of hematotoxicity see Table 2 below.

\section{Discussion}

mUCC is a disease with a poor prognosis associated with a limited overall survival despite therapy. "Real-life" data become more and more important in treating patients in the field of drug therapy in uro-oncology. Thus, it is interesting to compare the efficacy and safety data of clinical trials with those of patients in daily routine.

In our single center cohort a relatively large proportion of mUCC reached second- (85.4\%), third- (40\%) and even fourth-line (14.3\%) therapy leading to a mOS of 18 months. In contrast, Niegisch et $\mathrm{al}^{11}$ reported a lower proportion of $28.7 \%$ reaching second-line and $9 \%$ reaching third-line therapy. In their population only $31 \%$ of the patients had an ECOG of 0 at start of first-line therapy as well as a high proportion $(42 \%)$ suffered from liver metastases. In our cohort, $65.7 \%$ of the patients showed an ECOG of 0 at the beginning of chemotherapy and a lower proportion of $36.8 \%$ of liver metastases, so that the basic conditions of our patients were more favorable compared to the population of Niegisch et al. ${ }^{11,12}$

We found a positive correlation to mOS the more therapy lines patients had received: patients with only one therapy line showed a mOS of 10.8 months. In the case of two therapy lines (84.5\%) mOS increased up to 19 months. All these patients received $\mathrm{G} / \mathrm{C}$ polychemotherapy as first-line therapy. In addition, ORR of $31.4 \%$ and DCR of $62.8 \%$ under the second-line therapy were quite good. Patients reaching third-line therapy (40\%) showed the longest mOS of 29.5 months after second-line therapy with VFL $(50 \%)$ or $\mathrm{G} / \mathrm{P}(50 \%)$ reaching statistical significance $(p=0.041)$.

Studies about mOS in correlation to sequential therapy in mUCC are rare. A small Phase II-study analyzed the efficacy of $\mathrm{G} / \mathrm{P}$ as second line after failure of a MVAC therapy. Similar to our cohort the authors reported a mOS of 19 months with the beginning of second-line therapy. ${ }^{13}$ More often data about the OS starting with the second line are reported: mOS under VFL in second line ranges between 6.2 and 8.2 months. ${ }^{8,14,15}$ In contrast to our data Niegisch et $\mathrm{al}^{11}$ reported a mOS of 16.1 months under first-line and a mOS of 9.2 months under second-line therapy in a multicentre retrospective analysis. However, those patients with a mOS of 16.1 months received further therapies, whereas patients with a mOS of 10.8 months in our cohort only received one therapy line. Furthermore, our group of patients with one therapy line only consisted of six persons, whereas Niegisch et al analyzed 435 patients in first line, so that drawing a comparison might prove difficult. ${ }^{11}$

\section{First Line}

Overall, $85 \%$ of our patients received $\mathrm{G} / \mathrm{C}$ in first line due to a high proportion of patients with an ECOG of $0(65.7 \%)$ and a good renal function. Niegisch et $\mathrm{al}^{11}$ and Bamias et al ${ }^{16}$ reported only a proportion of $69 \%$ and $50 \%$ due to, inter alia, less patients with an ECOG of 0 (31 and 43\%). The aim at the point of therapy decision was to facilitate a therapy with $\mathrm{G} / \mathrm{C}$ to as many patients as possible as mOS under $\mathrm{G} / \mathrm{Cp}$ is much lower with 9.8 months compared to 12.8 months under G/C. ${ }^{17}$ mOS of 25 months under $\mathrm{G} / \mathrm{C}$ was higher compared to 12.7 and 14 months in the Phase III-studies of Bellmunt et $\mathrm{al}^{18}$ and von der Maase et $\mathrm{al}^{19,20}$ due to a high proportion of patients (91.4\%) in our analysis who received further chemotherapy. ${ }^{-}$mPFS under $\mathrm{G} / \mathrm{C}$ was 8.5 months which reflects - in clinical practice - the data of phase IIIstudies, that are around 7.6 and 7.7 months. ${ }^{18,19}$ ORR was $68.6 \%$ in our analysis. The ORR, that Bellmunt et al and von der Maase et al specified, was slightly lower (43.6 and $49.4 \%)^{18,20}$

\section{Second Line}

mOS of 7.5 months was comparable to 7.8 months in the phase II/III study of Albers et al. ${ }^{9}$ The mPFS of 7 months is located in the middle range compared to other studies, where mPFS was between 4 and 11 months. ${ }^{9,13,21,22}$ ORR in our analysis was $23.1 \%$ and lower than in different phase II-Studies. ${ }^{13,23}$ However, a direct comparison seems to be difficult because of heterogeneous cohorts and different prior therapies. ${ }^{13,22,23}$ 
mOS under VFL in second line was 8 months and slightly higher than in the registration trial (6.9 months). ${ }^{24}$ Consecutive treatment in our study was performed in $100 \%$ of the patients compared to only $28.9 \%$ of the Bellmunt cohort. ${ }^{8} \mathrm{mPFS}$ under VFL was 5 months and equals other retrospective analyses. ${ }^{14,25-29}$ The ORR of $40 \%$ in our study seems to be relatively high compared to other studies ( 12.5 and $29 \%$ ), probably due to the small case number and the "real life" setting. ${ }^{25-30}$

\section{Third Line}

The considerable mOS of 8.5 months of patients reaching third-line therapy seems to be in line with the mOS of 9 months under Cisplatin/Paclitaxel after failure of two platin-based previous therapies reported by Joung et al. ${ }^{31}$ But comparison is difficult due to different previous therapies and small case numbers. In general data about the efficacy of third-line therapy are rare.

\section{Toxicity}

Hematotoxicity was the most common side effect both in our analysis and in other studies.

The rate of grade $3 / 4$ toxicity under $\mathrm{G} / \mathrm{C}$ in first line was $85.7 \%$ : anaemia $28.6 \%$, thrombocytopenia $20 \%$, and neutropenia $37.1 \%$. The proportion of grade $3 / 4$ neutropenia and thrombocytopenia was higher in the study of Bellmunt et $\mathrm{al}^{18}$ and von der Maase et $\mathrm{al}^{20}$ : a neutropenia occurred in $50.5 \%$ and $71.1 \%$ of the cases, a thrombocytopenia in 52.1 and $57 \%$ of the patients. Probably this is due to our retrospective data collection.

Half of our patients under $\mathrm{G} / \mathrm{Cp}$ in first line suffered from anaemia grade $3 / 4$ and two thirds each had thrombopenia, leucopenia or neutropenia grade $3 / 4$. These proportions were higher than in an analysis of De Santis et al, ${ }^{32}$ where about $50 \%$ had every hematotoxicity mentioned above.

A grade $3 / 4$ toxicity under VFL in second line occurred in 58\%: anaemia $21.1 \%$, thrombocytopenia $5.3 \%$, and neutropenia $31.6 \%$. The rate of toxicity was higher in the cohort of Bellmunt (74.7\%) due to a higher proportion of patients with neutropenia of $50 \% .{ }^{8,24}$ The share of neutropenia under VFL is described as between 1.3 and $50 \%$ in the literature. Retz et $\mathrm{al}^{30}$ reported a rate of $1.3 \%$ in a cohort where an ECOG PS of max. 1 and an appropriate liver and renal function as well as a proper haematopoiesis were an inclusion criteria at the beginning of the therapy. In other studies neutropenia occurred in 9 to $17 \%$ of the cases. $^{26-29,33}$
The rate of anaemia and thrombocytopenia grade $3 / 4$ of $7.7 \%$ and $15.4 \%$ under $\mathrm{G} / \mathrm{P}$ in second line was relatively low and comparable to other retrospective studies. Likewise, the proportion of $38.5 \%$ of a neutropenia grade 3 was comparable to $30 \%$ and $32 \%$ in the analysis of Kanai and Sternberg et al. ${ }^{9,22,23,34}$

\section{Conclusion}

Our data show that a high proportion of patients reached second- $(84.5 \%)$ and third-line therapy (40\%) in "real-life" and that the number of therapy lines is associated with a better mOS. With three therapy lines patients reached a mOS of up to 29.5 months. ORR was advantageous in all therapy lines. Assessing the acceptable rate of toxicities in our analysis there is a good tolerability of chemotherapy in clinical routine in a very heterogenous patient group. In the meantime, immunotherapy agents were approved for therapy of mUCC and expanded the therapeutic options in daily routine. Nevertheless, the important question of the most promising sequence as well as prognostic biomarkers with the option to individualize therapy and optimize outcome has still to be answered in the future.

Our "real-life" data reveal that treatment of mUCC using chemotherapy is efficient and safe in daily routine and results from clinical trials can be confirmed. This underlines the good therapeutic option chemotherapy represents in patients with mUCC.

\section{Ethics}

As the study was done to investigate clinical data of patients treated solely at our institution approval of the local ethics committee (Ethics Committee, Faculty of Medicine Marburg) was therefore not required according to the German Ethics Committees regulations. The study was done in accordance with the Helsinki Declaration II and Standards of Good Clinical Practice. A patient consent to review the medical record was not required as only retrospective, anonymized data were analyzed that were collected for the daily use in clinical practice and no action was performed concerning the patient. Data were anonymized and maintained with confidentiality.

\section{Acknowledgments}

AH thanks Prof. Ulrich Koehler from the Department of Pneumonology of the University Hospital Marburg for his great effort - without his commitment, reliability and selfless support this manuscript never would have been published. 


\section{Disclosure}

The authors report no conflicts of interest in this work.

\section{References}

1. Pea K. Cancer in Germany in 2013/2014. 11th ed. Berlin: Robert Koch Institute (ed.) and the Association of Population-based Cancer Registries in Germany (ed); 2018.

2. Pagano F, Bassi P, Galetti TP, et al. Results of contemporary radical cystectomy for invasive bladder cancer: a clinicopathological study with an emphasis on the inadequacy of the tumor, nodes and metastases classification. J Urol. 1991;145(1):45-50. doi:10.1016/S00225347(17)38244-7

3. Stein JP, Lieskovsky G, Cote R, et al. Radical cystectomy in the treatment of invasive bladder cancer: long-term results in 1054 patients. J Clin Oncol. 2001;19(3):666-675. doi:10.1200/JCO.2001.19.3.666

4. Cheng L, Weaver AL, Leibovich BC, et al. Predicting the survival of bladder carcinoma patients treated with radical cystectomy. Cancer. 2000;88(10):2326-2332. doi:10.1002/(SICI)1097-0142(20000515) 88:10<2326::AID-CNCR17>3.0.CO;2-T

5. Ghoneim MA, el-Mekresh MM, el-Baz MA, el-Attar IA, Ashamallah A. Radical cystectomy for carcinoma of the bladder: critical evaluation of the results in 1026 cases. J Urol. 1997;158 (2):393-399. doi:10.1016/S0022-5347(01)64487-2

6. Dalbagni G, Genega E, Hashibe M, et al. Cystectomy for bladder cancer: a contemporary series. J Urol. 2001;165(4):1111-1116. doi:10.1016/S0022-5347(05)66440-3

7. Gebbia V, Testa A, Borsellino N, et al. Single agent $2^{\prime}, 2^{\prime}-$ difluorodeoxycytidine in the treatment of metastatic urothelial carcinoma: a phase II study. Clin Ter. 1999;150(1):11-15.

8. Bellmunt J, Theodore C, Demkov T, et al. Phase III trial of vinflunine plus best supportive care compared with best supportive care alone after a platinum-containing regimen in patients with advanced transitional cell carcinoma of the urothelial tract. J Clin Oncol. 2009;27 (27):4454-4461. doi:10.1200/JCO.2008.20.5534

9. Albers P, Park SI, Niegisch G, et al. Randomized phase III trial of 2nd line gemcitabine and paclitaxel chemotherapy in patients with advanced bladder cancer: short-term versus prolonged treatment [German Association of Urological Oncology (AUO) trial AB 20/ 99]. Ann Oncol. 2011;22(2):288-294. doi:10.1093/annonc/mdq398

10. Suzman DL, Agrawal S, Ning YM, et al. FDA approval summary: atezolizumab or pembrolizumab for the treatment of patients with advanced urothelial carcinoma ineligible for cisplatin-containing chemotherapy. Oncologist. 2019;24(4):563-569. doi:10.1634/theoncologist.2018-0084

11. Niegisch G, Gerullis H, Lin SW, et al. A real-world data study to evaluate treatment patterns, clinical characteristics and survival outcomes for first- and second-line treatment in locally advanced and metastatic urothelial cancer patients in Germany. J Cancer. 2018;9 (8):1337-1348. doi:10.7150/jca.23162

12. Matsumoto $\mathrm{R}$, Abe $\mathrm{T}$, Ishizaki $\mathrm{J}$, et al. Outcome and prognostic factors in metastatic urothelial carcinoma patients receiving second-line chemotherapy: an analysis of real-world clinical practice data in Japan. Jpn J Clin Oncol. 2018;48(8):771-776. doi:10.1093/ jjco/hyy094

13. Matsumoto K, Irie A, Satoh T, Okazaki M, Iwamura M, Baba S. Gemcitabine and paclitaxel chemotherapy as a second-line treatment for advanced or metastatic urothelial carcinoma. Int J Urol. 2007;14 (11):1000-1004; discussion 1004. doi:10.1111/j.1442-2042.2007. 01889.x

14. Hegele A, Goebell P, Matz U, Neuhaus T. Monotherapy with intravenous vinflunine in patients with advanced or metastatic urothelial cancer after failure of a platinum-containing regimen: a retrospective analysis of German routine data. Urol Int. 2014;92(2):174-179. doi:10.1159/000354751
15. Vaughn DJ, Srinivas S, Stadler WM, et al. Vinflunine in platinum-pretreated patients with locally advanced or metastatic urothelial carcinoma: results of a large phase 2 study. Cancer. 2009;115(18):4110-4117. doi:10.1002/cncr.24460

16. Bamias A, Tzannis K, Harshman LC, et al. Impact of contemporary patterns of chemotherapy utilization on survival in patients with advanced cancer of the urinary tract: a Retrospective International Study of Invasive/Advanced Cancer of the Urothelium (RISC). Ann Oncol. 2018;29(2):361-369. doi:10.1093/annonc/mdx692

17. Dogliotti L, Carteni G, Siena S, et al. Gemcitabine plus cisplatin versus gemcitabine plus carboplatin as first-line chemotherapy in advanced transitional cell carcinoma of the urothelium: results of a randomized phase 2 trial. Eur Urol. 2007;52(1):134-141. doi:10.1016/j.eururo.2006.12.029

18. Bellmunt J, von der Maase H, Mead GM, et al. Randomized phase III study comparing paclitaxel/cisplatin/gemcitabine and gemcitabine/ cisplatin in patients with locally advanced or metastatic urothelial cancer without prior systemic therapy: EORTC Intergroup Study 30987. J Clin Oncol. 2012;30(10):1107-1113. doi:10.1200/JCO. 2011.38.6979

19. von der Maase H, Sengelov L, Roberts JT, et al. Long-term survival results of a randomized trial comparing gemcitabine plus cisplatin, with methotrexate, vinblastine, doxorubicin, plus cisplatin in patients with bladder cancer. $J$ Clin Oncol. 2005;23(21):4602-4608. doi:10.1200/JCO.2005.07.757

20. von der Maase H, Hansen SW, Roberts JT, et al. Gemcitabine and cisplatin versus methotrexate, vinblastine, doxorubicin, and cisplatin in advanced or metastatic bladder cancer: results of a large, randomized, multinational, multicenter, phase III study. J Clin Oncol. 2000;18(17):3068-3077. doi:10.1200/JCO.2000.18.17.3068

21. Fechner G, Siener R, Reimann M, Kobalz L, Albers P; German Association Of Urologic Oncology Bladder Cancer Study Group. Randomised phase II trial of gemcitabine and paclitaxel second-line chemotherapy in patients with transitional cell carcinoma (AUO Trial AB 20/99). Int J Clin Pract. 2006;60(1):27-31. doi:10.1111/j.17421241.2005.00663.x

22. Ikeda M, Matsumoto K, Tabata K, et al. Combination of gemcitabine and paclitaxel is a favorable option for patients with advanced or metastatic urothelial carcinoma previously treated with cisplatin-based chemotherapy. Jpn J Clin Oncol. 2011;41(10):1214-1220. doi:10. 1093/jjco/hyr131

23. Kanai K, Kikuchi E, Ohigashi T, et al. Gemcitabine and paclitaxel chemotherapy for advanced urothelial carcinoma in patients who have received prior cisplatin-based chemotherapy. Int J Clin Oncol. 2008;13(6):510-514. doi:10.1007/s10147-008-0779-x

24. Bellmunt J, Fougeray R, Rosenberg JE, et al. Long-term survival results of a randomized phase III trial of vinflunine plus best supportive care versus best supportive care alone in advanced urothelial carcinoma patients after failure of platinum-based chemotherapy. Ann Oncol. 2013;24(6):1466-1472. doi:10.1093/annonc/mdt007

25. Hussain SA, Ansari J, Huddart R, et al. VICTOR: vinflunine in advanced metastatic transitional cell carcinoma of the urothelium: a retrospective analysis of the use of vinflunine in multi-centre real life setting as second line chemotherapy through free of charge programme for patients in the UK and Ireland. Int $J$ Oncol. 2017;50(3):768-772. doi:10.3892/ijo.2017.3847

26. Medioni J, Di Palma M, Guillot A, Spaeth D, Theodore C. Efficacy and safety of Vinflunine for advanced or metastatic urothelial carcinoma in routine practice based on the French multi-centre CURVE study. BMC Cancer. 2016;16:217. doi:10.1186/s12885-016-2262-9

27. Velasco GD, Chirivella I, Gonzalez-Grajera B, et al. Vinflunine (VFL) as second-line chemotherapy for patients with transitional cell carcinoma of the urothelium (TCCU): a multicenter retrospective study. J Clin Oncol. 2013;31(15_suppl):e15620-e15620. doi:10.12 00/jco.2013.31.15_suppl.e15620 
28. Castellano D, Puente J, de Velasco G, et al. Safety and effectiveness of vinflunine in patients with metastatic transitional cell carcinoma of the urothelial tract after failure of one platinum-based systemic therapy in clinical practice. BMC Cancer. 2014;14:779. doi:10.1186/ 1471-2407-14-779

29. Passalacqua R, Lazzarelli S, Donini M, et al. Real-life clinical practice results with vinflunine in patients with relapsed platinum-treated metastatic urothelial carcinoma: an Italian multicenter study (MOVIE-GOIRC 01-2014). BMC Cancer. 2017;17(1):493. doi:10.1186/s12885-017-3466-3

30. Retz M, de Geeter P, Goebell PJ, Matz U, de Schultz W, Hegele A. Vinflunine in routine clinical practice for the treatment of advanced or metastatic urothelial cell carcinoma - data from a prospective, multicenter experience. BMC Cancer. 2015;15:455. doi:10.1186/s12885-015-1434-3

31. Joung JY, Kwon WA, Cho IC, et al. Paclitaxel and cisplatin chemotherapy for metastatic urothelial carcinoma after failure of two courses of platinum-based regimens. Int J Urol. 2011;18(5):350-357. doi:10.1111/j.1442-2042.2011.02735.x
32. De Santis M, Bellmunt J, Mead G, et al. Randomized phase II/III trial assessing gemcitabine/carboplatin and methotrexate/carboplatin/vinblastine in patients with advanced urothelial cancer who are unfit for cisplatin-based chemotherapy: EORTC study 30986. J Clin Oncol. 2012;30(2):191-199. doi:10.1200/JCO.2011.37.3571

33. Bamias A, Hegele A, Medioni J, et al. Vinflunine in the treatment of relapsed metastatic urothelial cancer: a systematic review and meta-analysis of real-world series. Crit Rev Oncol Hematol. 2019;140:80-87. doi:10.1016/j.critrevonc.2019.05.006

34. Sternberg CN, Calabro F, Pizzocaro G, Marini L, Schnetzer S, Sella A. Chemotherapy with an every-2-week regimen of gemcitabine and paclitaxel in patients with transitional cell carcinoma who have received prior cisplatin-based therapy. Cancer. 2001;92(12):2993-2998. doi:10.1002/ 1097-0142(20011215)92:12<2993::AID-CNCR10108>3.0.CO;2-2

\section{Publish your work in this journal}

Cancer Management and Research is an international, peer-reviewed open access journal focusing on cancer research and the optimal use of preventative and integrated treatment interventions to achieve improved outcomes, enhanced survival and quality of life for the cancer patient.
The manuscript management system is completely online and includes a very quick and fair peer-review system, which is all easy to use Visit http://www.dovepress.com/testimonials.php to read real quotes from published authors. 